\title{
TORNEIO DE ROBÓTICA COMO MÉTODO DE APRENDIZAGEM BASEADA EM PROBLEMAS NA ENGENHARIA DE AUTOMAÇÃO INDUSTRIAL
}

Danilo Magone Duarte Martins - danilomagone@gmail.com

Centro Federal de Educação Tecnológica de Minas Gerais- CEFET-MG

Av. Min. Olavo Drummond, 25 - Amazonas

38180-510- Araxá - MG

Nivia Angelica Chaves Viana Silva - niviabvianna@gmail.com

Centro Federal de Educação Tecnológica de Minas Gerais- CEFET-MG

Av. Min. Olavo Drummond, 25 - Amazonas

38180-510- Araxá - MG

Resumo:Em face à dificuldade encontrada pelas universidades e instituições de ensino em acompanhar as rápidas mudanças tecnológicas e sociais vivenciadas atualmente, metodologias ativas de ensino têm sido desenvolvidas como uma tentativa de aproximar o curso de engenharia do mercado de trabalho. Entre essas metodologias está a aprendizagem baseada em problemas (PBL), onde podem ser desenvolvidas habilidades técnicas, de pesquisa e de trabalho em grupo. As competições acadêmicas podem servir como um método de aplicação do PBL, incentivando os alunos, através da competitividade, a buscar soluções, técnicas e de conflitos, em prol de um desempenho melhor. Dessa forma, os alunos do Programa de Educação Tutorial do CEFET-MG, campus de Araxá, realizaram a quinta edição do Torneio de Robótica do CEFET-MG (TORC), uma competição de robôs autônomos na modalidade de seguidores de trilha. O objetivo desse trabalho foi verificar se $o$ TORC serviu como um método eficiente de aplicação do PBL e quais foram os benefícios gerados para os alunos de graduação participantes. Para isso, aplicou-se um formulário sobre a experiência dos competidores durante o evento. Os resultados mostraram que, no geral, os alunos de graduação participantes se sentiram motivados a encontrar a solução dos desafios enfrentados e todos os alunos concordaram que utilizaram conceitos teóricos vistos durante seu curso na construção do robô, sendo este um resultado significativo.

Palavras-chave: Problem Based Learning, Torneio de Robótica, Robótica Educacional,PBL.

\section{INTRODUÇÃO}

A globalização e os constantes avanços tecnológicos trouxeram a tona a necessidade de profissionais engenheiros com habilidades além das tradicionais desenvolvidas nas universidades. A formação e a estrutura de ensino não possuem condições para acompanhar as mudanças no mercado de trabalho, considerando o distanciamento entre o que é ensinado na teoria e a rapidez nas transformações e no conhecimento científico e tecnológico (WOODS $\mathrm{Jr}, 2000)$.

Além disso, de acordo com um estudo realizado pelo Instituto de Pesquisa Econômica Aplicada (IPEA) menos de 30\% dos alunos de engenharia formados no Brasil experienciaram cursos de melhor padrão, o que evidencia problemas qualitativos quanto a formação em engenharia (Nascimento et. al., 2010). Dessa forma, torna-se clara a necessidade de debater 
atividades complementares para o currículo das instituições de ensino superior.

A Problem-Based Learning (PBL) apesar de desenvolvida na década de 60 para o estudo de medicina, pode ser considerado uma metodologia avançada em termos de aprendizado em qualquer área do sistema educacional, uma vez que, diferente das metodologias tradicionais com o enfoque em soluções, na PBL dois pontos básicos são levados em consideração, o trabalho em problemas significativos, e a busca de conhecimento para a solução de uma situação desconhecida (AUSUBEL et al.,1980).

Na PBL o ensino é descentralizado, o que significa que o professor passa a ser visto como um agente de ensino e não somente como um transmissor, que facilita o aprendizado dos alunos sem oferecer necessariamente as respostas, e incentiva a busca por outras formas de visualização dos problemas. Além disso, a metodologia é trabalhada em grupo, e segundo Pozo (2002), realizar atividades em grupo é melhor se comparado a individualmente pois os resultados são melhores quando há cooperação mútua.

Nesse sentido, as competições acadêmicas aceleram o processo de aprendizagem por incentivar a solução de problemas, aplicando conceitos teóricos, o trabalho em equipe e a busca por conhecimentos e habilidades além das adquiridas em sala de aula (FERNANDES,2018).Com a percepção da necessidade de incentivo a diferentes metodologias e do anseio dos estudantes de engenharia para melhoria do processo de ensinoaprendizagem os participantes do Programa de Educação Tutorial (PET) do CEFET-MG de Araxá realizaram a quinta edição do Torneio de Robótica do CEFET-MG (TORC).O TORC é um projeto criado em 2012 e trata-se de uma competição de robôs autônomos na modalidade de seguidores de trilha, totalmente desenvolvidos pelos participantes. Esta consiste em robôs que devem seguir um caminho pré-determinado, no menor tempo possível.

Os registros do uso da robótica educacional são muitos. No artigo de França et al (2019), é descrita uma competição de robótica com alunos do primeiro semestre de Engenharia Elétrica. Ao final da competição os alunos responderam um formulário sobre a sua experiência no projeto. Os resultados mostraram que os alunos consideraram a atividade motivante e que o projeto ajudou os alunos no entendimento e prática da teoria. Em França et al (2016) a robótica também foi utilizada com alunos ingressantes na Engenharia Elétrica. Ao fim da pesquisa, foram destacados pontos como o trabalho em equipe, multidisciplinaridade e a motivação aos alunos permanecerem no curso.

Segundo o artigo de Vilhete et al (2002), os problemas práticos sugeridos durante a competição de robótica possibilitaram a aplicação dos conceitos teóricos antes vistos em sala e ainda o aprendizado de novos tópicos, e no fim da competição foi possível notar que a desenvolver o projeto em grupo, trouxe aprendizados como a cooperação, ética de trabalho e ainda o crescimento individual. Objetivou-se nesse trabalho verificar se o TORC serviu como um método eficiente de aplicação do PBL e quais foram os benefícios gerados para os alunos de graduação participantes.

\section{METODOLOGIA}

Foi fornecido pelos alunos participantes do Programa de Educação Tutorial e um professor-tutor um minicurso com o objetivo de introduzir aos participantes conceitos básicos para o desenvolvimento do robô. Para isso, foram apresentadas as características e regras da competição, e como organizar o projeto dividindo-o em partes como eletrônica, mecânica, financeira e gestão de recursos. De forma a instigar os competidores a buscarem por soluções durante a competição bem como reforçar a importância da fase de planejamento e decisões no projeto, também lhes foi apresentado diferentes sensores, microcontroladores e até mesmo 
CCOBENCE 2020 (C)

"Os desafios para formar hoje o engenheiro do amanhã"
$\mathrm{Ol} \mathrm{a} \mathrm{O3}$ de dezembro Evento On-line

diferentes tipos de motores. A escolha ou não desses, foram da exclusiva vontade dos competidores.

Figura 1 - Minicurso fornecido.

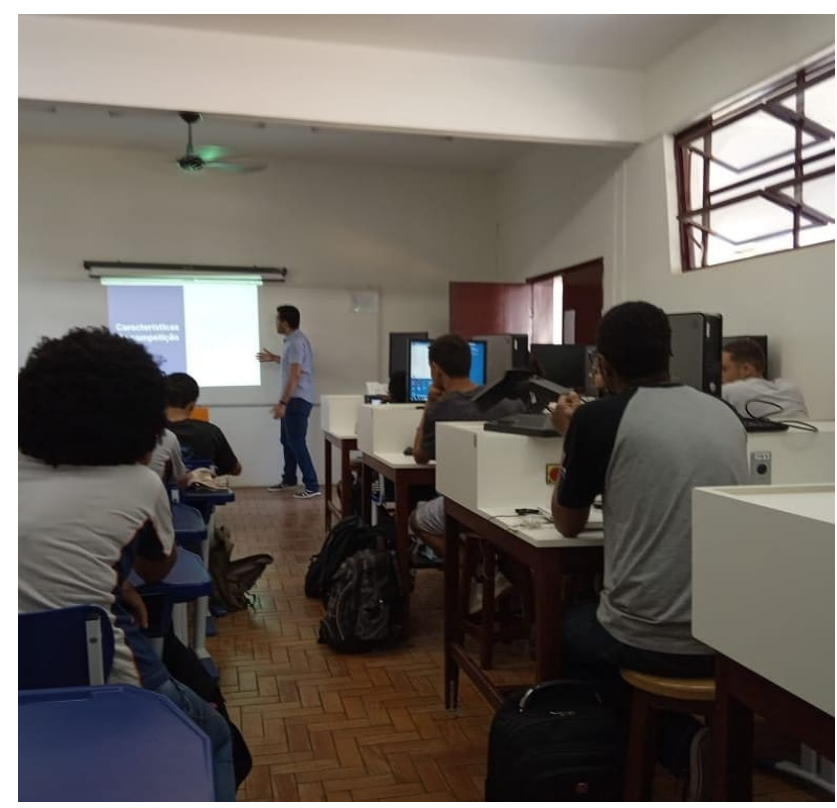

Fonte: Autores, 2019

O torneio contou com equipes do ensino médio técnico e graduação além de ser aberto para a participação de alunos de outras instituições. Cada equipe era composta por três integrantes que deviam desenvolver seus robôs, sem a possibilidade de utilização de kits préfabricados. Dessa forma obrigou-se as equipes a desenvolverem todo o processo de criação de um robô seguidor de trilha. A quinta edição do TORC contou com cinco equipes no evento principal, sendo duas compostas exclusivamente por alunos da graduação, duas por alunos do ensino médio técnico e uma equipe mista com graduação e técnico. Sendo assim, participaram oito alunos da Engenharia de Automação Industrial, todos alunos do próprio CEFET-MG.

A competição foi realizada na modalidade seguidor de trilha, onde o robô precisava realizar o trajeto pré-determinado no menor tempo possível. Para indicar o caminho pelo qual o robô devia seguir, havia uma linha de referência no meio da pista em todo o trajeto e alguns obstáculos como rampas, túneis, curvas, cruzamentos e encruzilhadas (Figura 2). 
Figura 2 - Pista do torneio de robótica.

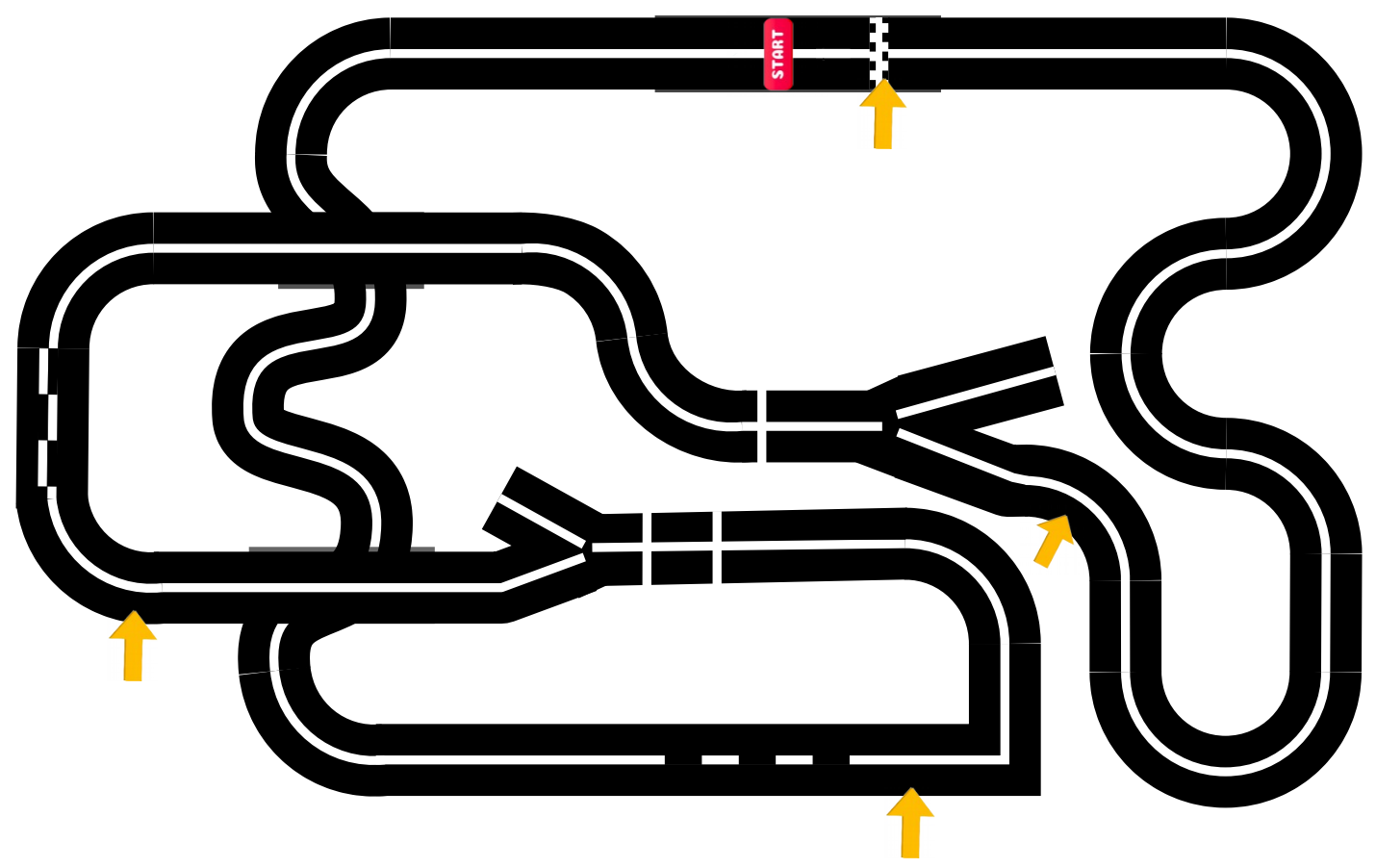

Fonte: Autores,2019

A pista possuía quatro checkpoints distribuídos ao longo do trajeto (Setas mostradas na Figura 2). Ao alcançar um checkpoint a equipe conquistava vinte e cinco pontos. Havia também uma pontuação de dez pontos às equipes cujo robô fosse capaz de finalizar o percurso em cima da última elevação da pista (o mesmo local onde se iniciou o percurso) parando por, no mínimo 5 segundos. O protótipo não poderia partir imediatamente após o seu acionamento. Sendo assim, o mesmo deveria portar algum mecanismo de atraso na partida, de modo que o carrinho partisse no mínimo dois segundos e no máximo trinta segundos após o último contato com o integrante da equipe, o não cumprimento dessa regra resultava na anulação da bateria e nenhuma pontuação era ganha pela equipe.

Durante a volta, caso o protótipo saísse completamente da pista ou parasse na pista por mais de 10 (dez) segundos ou escolha o caminho errado ao chegar a uma bifurcação, a bateria era encerrada e a equipe será pontuada de acordo com o último checkpoint alcançado. Em caso de empate em pontos, o critério de desempate usado foi o tempo com que cada uma delas atingiu o último checkpoint alcançado, classificando-se do menor tempo para o maior. $\mathrm{O}$ tempo de percurso foi medido eletronicamente. Uma que vez que se trata de uma competição voltada para o ensino técnico e graduação, não foi permitido aos participantes a utilização de kits de robótica, como por exemplo, o kit LEGO, dessa forma obrigou-se as equipes a desenvolverem todo o processo de criação de um robô seguidor de trilha. Os protótipos poderiam ter um peso máximo de $0,9 \mathrm{~kg}$ e deveriam transportar consigo sua própria fonte de energia elétrica, sendo então proibida a utilização de qualquer fonte externa. Além disso, não era permitido nenhum controle externo, humano ou computacional durante as baterias e sendo assim, não era permitido que o robô tivesse nenhum dispositivo de comunicação sem fio.

As equipes deviam enviar um relatório da construção do robô à comissão de organização do torneio, tendo caráter eliminatório e as equipes que não atingissem sessenta por cento de aproveitamento seriam eliminadas. Depois de enviado o relatório, as equipes não poderiam utilizar nenhuma peça diferente daquelas declaradas previamente. Nenhuma equipe foi 
eliminada nesta etapa. A tabela 1 mostra como foram distribuídos os pontos para avaliação dos relatórios. Os relatórios serviram para manter a integridade do evento.

Tabela 1 - Pontuação do relatório de competição.

\begin{tabular}{|c|c|}
\hline Tópico & Pontuação atribuída \\
\hline Introdução & 0,5 \\
\hline Materiais & 1,5 \\
\hline Desenvolvimento & 7,0 \\
\hline Conclusão & 1,0 \\
\hline
\end{tabular}

Fonte: Autores,2020

O torneio foi composto de duas fases: classificatória (Figura 3) e final. Durante a fase classificatória foram realizadas três baterias de competição. A maior pontuação conquistada em uma bateria foi considerada a pontuação final da equipe nesta fase. Foram classificadas para a fase final as três melhores equipes da fase classificatória. $\mathrm{Na}$ fase final houve novamente três baterias. Assim como na fase classificatória, as equipes que disputaram as baterias tiveram somente a melhor pontuação considerada em seu placar final.

Figura 3 - Torneio de Robótica do CEFET-MG.

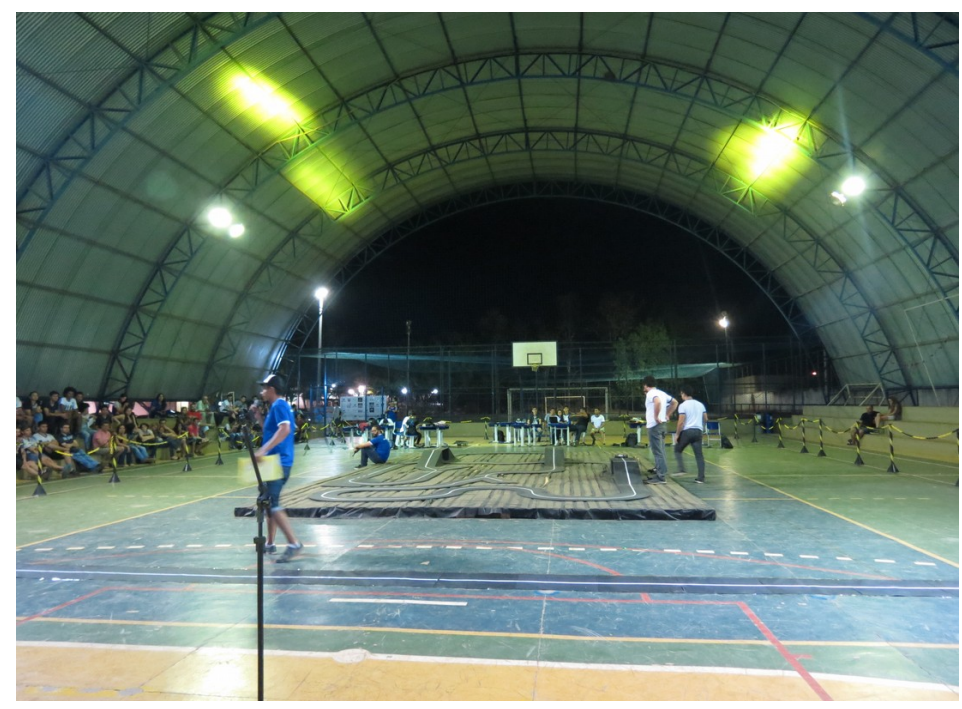

Fonte: Autores, 2019

\section{RESULTADOS}

Todas as regras e obstáculos na pista foram pensados a fim de possibilitar uma experiência desafiadora aos participantes que os motivassem na busca por soluções. Por isso, ao perceber que a maioria das equipes estavam com dificuldade em realizar a curva de $90^{\circ}$, a organização do torneio decidiu se reunir com os capitães de cada equipe e optou por remover esta curva, para que possibilitasse aos alunos buscar soluções pros demais obstáculos e não somente a curva em questão.

Das cinco equipes participantes do torneio, nenhuma equipe conseguiu completar todo o trajeto da pista. Entre as três equipes com alunos da graduação, a equipe campeã conseguiu ultrapassar um total de três checkpoints, conquistando assim setenta e cinco pontos. Uma equipe conquistou um checkpoint e uma equipe não conseguiu nenhum checkpoint.Porém, mais importante que o resultado final obtido na pista de competição é o aprendizado durante o processo de construção do robô e durante o evento em si. 
(C) COBENGE

"Os desafios para formar hoje o engenheiro do amanhã"
$\mathrm{Ol} \mathrm{a} \mathrm{O} 3$ de dezembro Evento On-line

Por isso, após o evento, foi pedido aos participantes que respondessem um formulário com questões sobre a sua experiência no TORC e os benefícios da competição. Todos os oito alunos de graduação que competiram no torneio responderam o formulário. O formulário consistia em afirmações as quais os entrevistados deveriam dizer se concordavam, plenamente ou em partes, ou discordavam plenamente ou partes.

A totalidade dos alunos entrevistados concordou, parcial $(42,9 \%)$ ou plenamente $(57,1 \%)$, que foi necessário aplicar conceitos teóricos estudados durante o curso para a criação do robô (Figura 4). Dessa forma, fica evidente que, para os participantes, o TORC foi uma forma de praticar habilidades inerentes ao seu curso de graduação.

Figura 4 -Aplicação de conceitos teóricos.

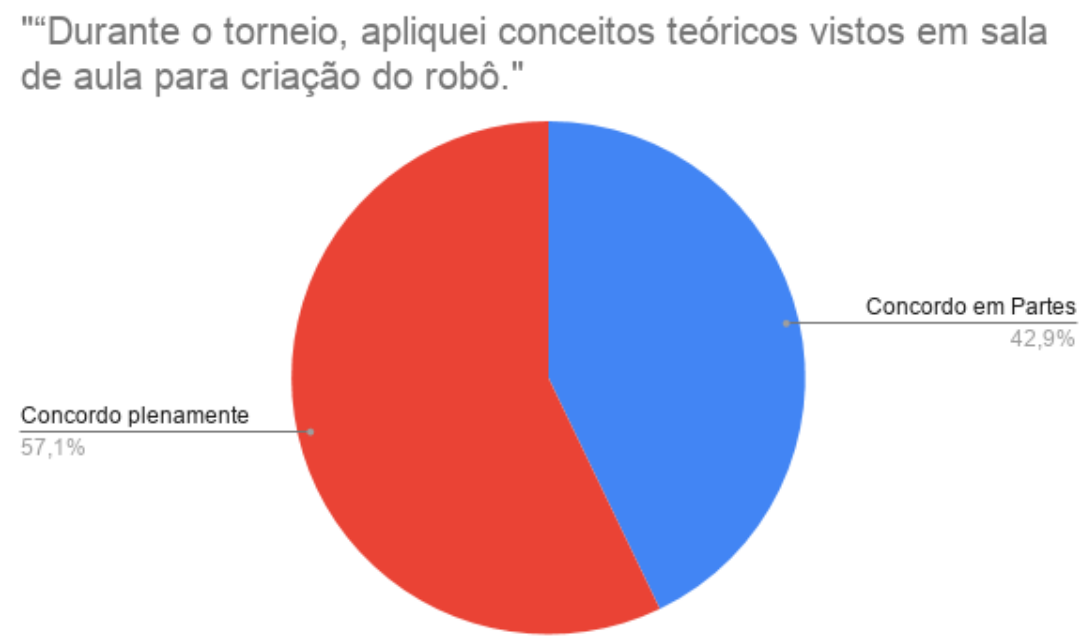

Fonte: Autores, 2020

Com relação às dificuldades encontradas (Figura 5), 71,4\% concordou totalmente que tiveram alguma dificuldade na execução prática da construção e 28,6\% concordou parcialmente. Na mesma proporção os entrevistados concordaram que precisaram aprender conteúdos novos para a construção do robô.

Figura 5 - Dificuldades em execução.

"Tive dificuldades em execuções práticas da construção".

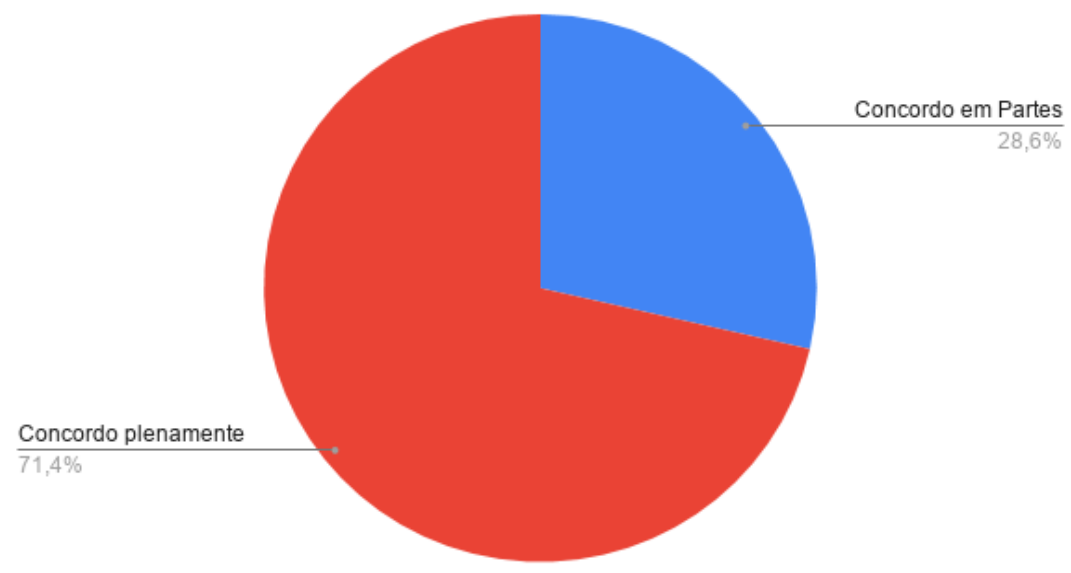

Fonte: Autores, 2020 
(C) COBENGE

"Os desafios para formar hoje o engenheiro do amanhã"
$\mathrm{Ol} \mathrm{a} \mathrm{O3}$ de dezembro Evento On-line

A maioria (71,4\% plenamente e $14,3 \%$ parcialmente), porém, disse que se sentiu motivada em encontrar soluções para os problemas encontrados. Apenas 14,3\% discordaram parcialmente (Figura 6). Percebe-se, portanto, que diante de um problema encontrado durante o evento, a maioria dos participantes se sentiu motivada a buscar soluções, inclusive buscando por novos conhecimentos em prol de progredir na competição.

Figura 6 - Motivação .

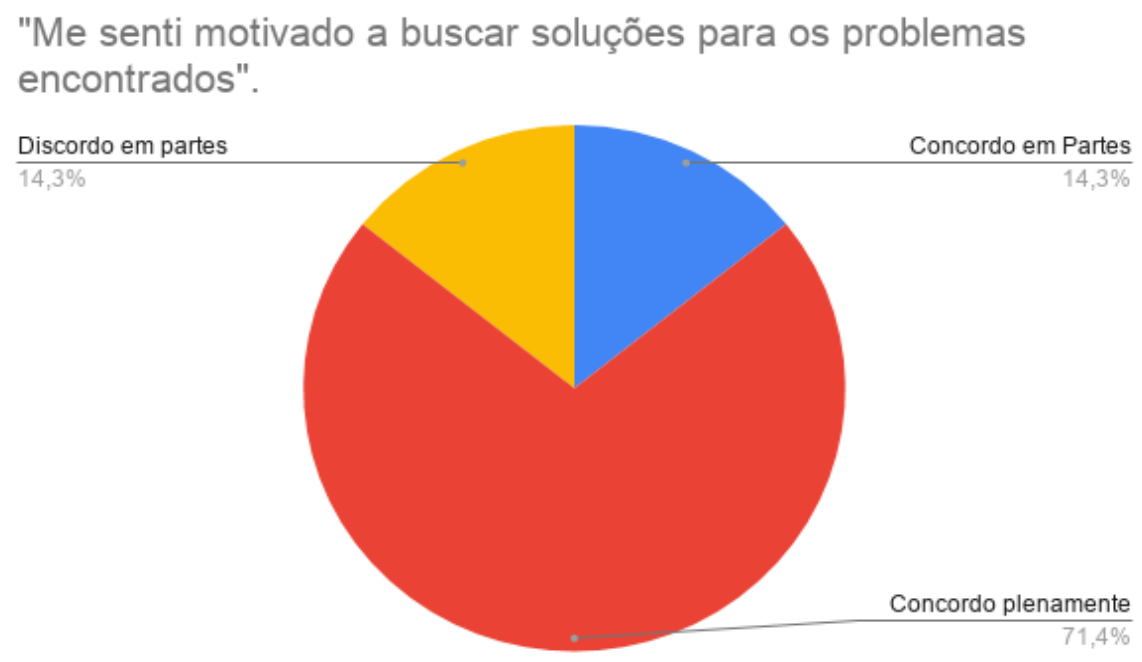

Fonte: Autores, 2020

Além disso, embora nenhuma equipe tenha concluído todo o percurso de prova, $71,4 \%$ concordaram plenamente e $28,6 \%$ concordaram parcialmente (Figura 7) que se sentiram aptos a participar do TORC, o que mostra, junto aos resultados apresentados acima, que a dificuldade imposta pelos desafios técnicos apresentados na pista foi o suficiente apenas para motivar os alunos, sem que os desanimasse na busca da solução dos problemas enfrentados.

Figura 7 - Aptidão.

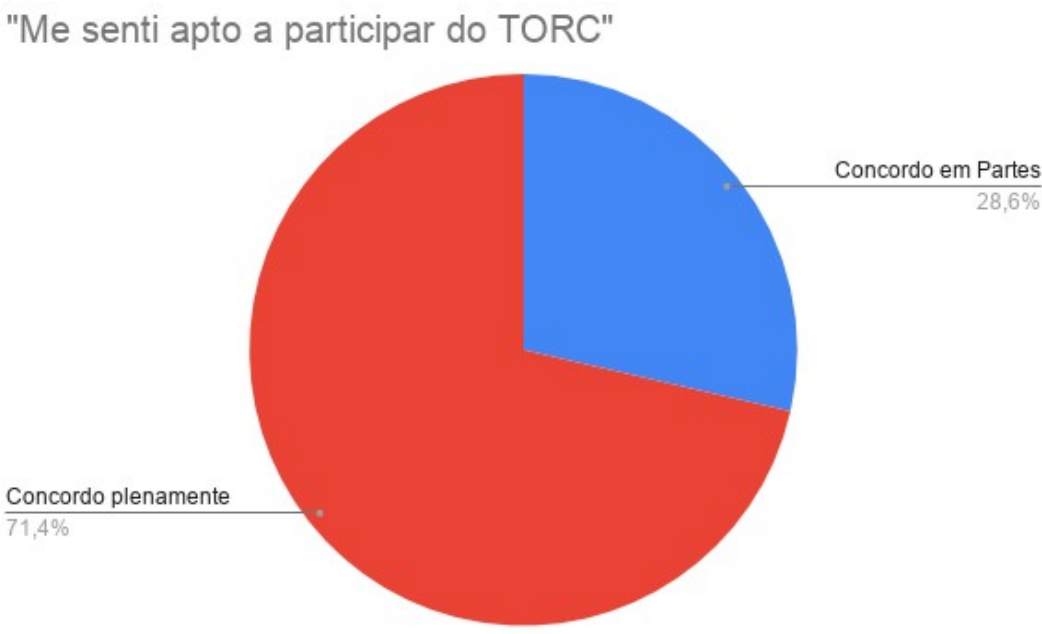

Fonte: Autores, 2020 


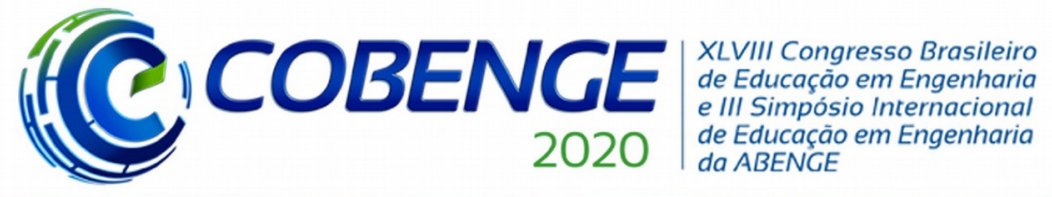

"Os desafios para formar hoje o engenheiro do amanhã"

Nesse sentido, uma equipe escreveu no seu relatório de competição

A possibilidade de projetar um robô, aplicar o conteúdo aprendido na sala de aula e poder participar de uma competição é uma maneira eficiente de motivar os alunos. Além disso, coloca o autodidatismo em prática uma vez que foi necessário buscar alguns conhecimentos além do que havia sido aprendido no curso até o momento.

Essa declaração reforça os resultados obtidos pela pesquisa, mostrando os pontos positivos da participação do TORC na visão dos próprios competidores. Sobre a multidisciplinaridade do torneio, $85,7 \%$ dos que responderam a pesquisa concordaram plenamente que utilizaram de conceitos de diferentes áreas do conhecimento para a construção do robô e 14,3\% concordaram parcialmente. Quanto ao trabalho em grupo, 85,7\% disseram concordar totalmente que trabalharam bem em equipe, enquanto 14,3\% discordaram parcialmente (Figura 8).

Figura 8 - Trabalho em equipe.

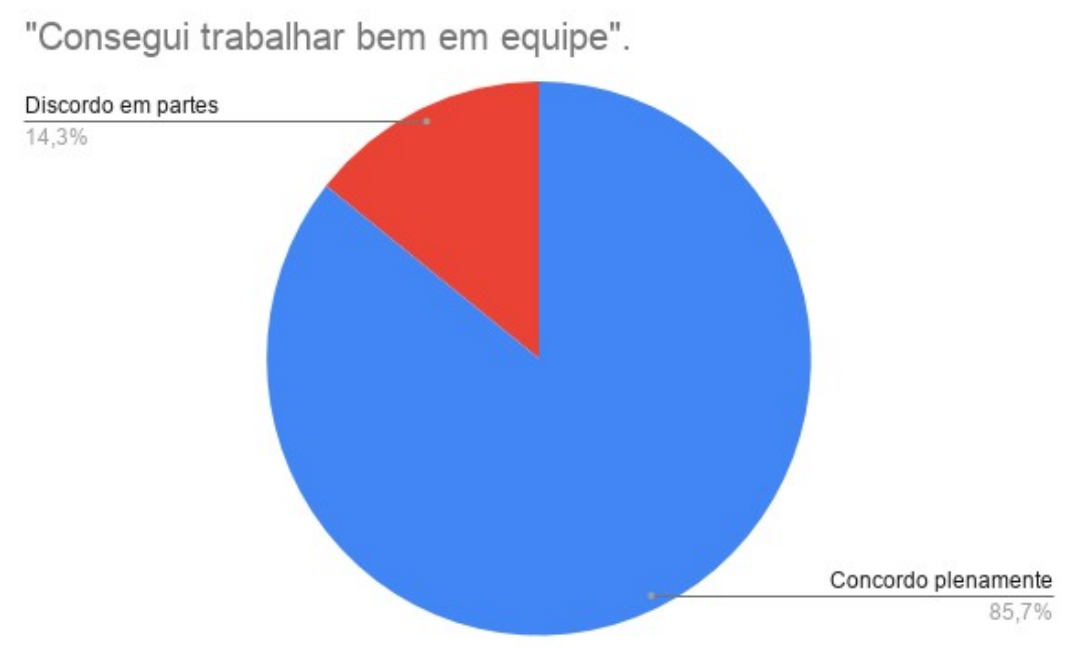

Fonte: Autores, 2020

A Figura 9 mostra o resultado da pesquisa referente à afirmativa:"Modifiquei de alguma forma meu comportamento durante o trabalho em equipe". A maior parte dos participantes terem discordado (42,9\% plenamente e 14,3\% em partes), sendo possível inferir que, levando em consideração o resultado do item anterior, a maioria dos alunos não sentiu a necessidade de alterar seu comportamento interpessoal para que houvesse uma melhora no desempenho. Ainda assim, uma parcela considerável dos entrevistados concordou que modificou o seu comportamento, sendo que 14,3\% concordam plenamente e 28,6\% concordaram em partes. 
Figura 9- Comportamento em equipe.

\begin{abstract}
"Modifiquei de alguma forma meu comportamento durante o trabalho em equipe".
\end{abstract}

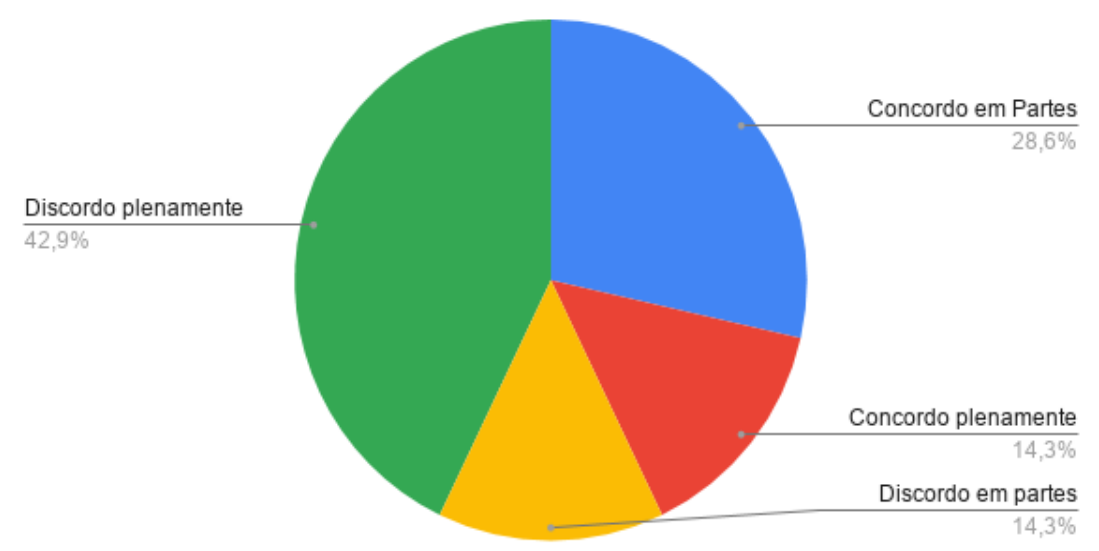

Fonte: Autores, 2020

Todos os participantes da graduação concordaram plenamente em dizer que participariam novamente do TORC, o que sugere que, no geral, todos consideraram o evento uma experiência positiva. Da mesma forma, todos os alunos concordaram plenamente que indicaria a participação no torneio a um colega.

\title{
4 CONSIDERAÇÕES FINAIS
}

O Torneio de Robótica do CEFET-MG cumpriu seus objetivos. A maioria dos alunos concordou não somente que o TORC motivou por meio da competitividade os alunos a praticar conceitos do curso de engenharia, mas também que os incentivou a buscar conhecimentos além daqueles vistos em sala de aula. Uma equipe comentou em seu relatório de competição: "A experiência de participar deste torneio está sendo muito positiva, à medida que estão agregando novos conhecimentos e experiências a nós, competidores.” Nesse sentido, pode-se dizer que a escolha da robótica como tema do torneio foi acertada, pois está intimamente ligada com o curso de graduação Engenharia de Automação Industrial possibilitando assim, o aprendizado citado. Outro objetivo da competição era desenvolver habilidades de relacionamento interpessoal e trabalho em grupo. A partir da pesquisa feita, nota-se que este objetivo também foi cumprido uma vez que a maior parte dos alunos disse não ter tido problemas com a sua equipe. Dessa forma, a partir da pesquisa apresentada e dos relatos dos alunos, pode-se afirmar que o Torneio de Robótica do CEFET-MG foi efetivo em ser um método de aprendizagem baseada em problemas.

Para as próximas edições, o objetivo será alcançar mais equipes, se possível atingindo alunos de outras instituições, aumentando as divulgações nas mídias sociais e divulgação no próprio campus do CEFET, que segundo a pesquisa foram os dois meios de divulgação mais efetivos. Além disso, será importante fornecer mais aulas durante o mini-curso a fim de alcançar resultados técnicos melhores, uma vez que nenhuma equipe foi capaz de completar a pista. Por fim, espera-se que mais eventos desse tipo sejam realizados, visto o benefício que o evento teve para os alunos participantes.

\section{REFERÊNCIAS}


AUSUBEL, D. P.; NOVAK, J. D.; HANESIAN, H. Psicologia Educacional, 2 ed. Rio de Janeiro:Interamericana, 1980.

FERNANDES, Rivalina Maria Macêdo et al. Competições de conhecimentos universitários: método inovador de incentivo à aprendizagem. Id On Line: Revista Multidiciplinar e de Pisicologia, São Paulo, v. 12, n. 42, p. 861-875, 2018. Semanal. Editora Adjunta do Periódico Científico Amadeus International Multidisciplinary Journal. Disponível em: http://idonline.emnuvens.com.br/id. Acesso em: 20 maio 2020.

FRANÇA, Allan Alex de et al. Utilização da robótica educacional na disciplina de Introdução à engenharia elétrica do IFPB como agente motivador para permanência no curso de Engenharia Elétrica. In: $6^{a}$ Mostra Nacional de Robótica, 2016. Anais. Recife, 2016.

FRANÇA, Celso A. de et al. Aprendizagem baseada em projetos(PjBL) através da competição de robôs. In: XLVII Congresso Brasileiro de Educação em Engenharia, 2019. Anais. Fortaleza, 2019.

VILHETE, João et al .Uma Abordagem Prático-Pedagógica para o Ensino de Robótica em Ciência e Engenharia de Computação. In: XIII SIMPÓSIO BRASILEIRO DE INFORMÁTICA NA EDUCAÇÃO, 2002, Porto Alegre. Campinas: Sbie, 2002. v. 1, p. 429438.

POZO, J. I. Aprendizes e mestres: a nova cultura da aprendizagem. Porto Alegre: Artmed, 2002.

WOOD JR, Thomaz. Reformando o ensino e o aprendizado de gestão da produção e operações. In: SIMPOI, 2., 2000. São Paulo. Anais. São Paulo: EAG/FGV, 2000.

\section{ROBOTICS TOURNAMENT AS A METHOD OF PROBLEM BASED LEARNING IN INDUSTRIAL AUTOMATION ENGINEERING}

Abstract: In view of the difficulty faced by universities and educational institutions in keeping up with the fast technological and social changes experienced today, active teaching methodologies have been developed as an attempt to bring the engineering course closer to the labor market. Among these methodologies there is the problem-based learning (PBL), in wich technical, researching and teamwork skills can be developed. Academic competitions might serve as a PBL applying method, encouraging students, through competitiveness, to seek solutions, technical and of conflicts, in order to perform better. Thus, the students of the Tutorial Education Program of CEFET-MG, at Araxá campus, held the fifth edition of the CEFET-MG Robotics Tournament (TORC), a competition of trail track autonomous robots. The goal of this work was to verify if the TORC served as an efficient PBL applying method and what were the benefits generated for the participants. Therefore, a form was applied about the experience of the competitors during the event. The results showed that, in general, the participating students felt motivated to find the solution of the challenges faced and all students agreed that they used theoretical concepts seen during their course in the construction of the robot, this being a significant result.

Keywords: Problem Based Learning,Robotics Tournament,Educational Robotics,PBL. 